\title{
RISK FACTORS FOR MALNUTRITION IN SENIORS AGED 75+ LIVING IN HOME ENVIRONMENT IN SELECTED REGIONS OF THE CZECH REPUBLIC
}

\author{
Iva Brabcová1, Marie Trešlová1, Sylva Bártlová1, Jitka Vacková2, Valerie Tóthová1, Lenka Motlová2 \\ ${ }^{1}$ Institute of Nursing, Midwifery and Emergency Care, Faculty of Health and Social Studies, University of South Bohemia, České Budèjovice, \\ Czech Republic \\ 2Institute of Social and Social-pedagogical Sciences, Faculty of Health and Social Studies, University of South Bohemia, České Budějovice, \\ Czech Republic
}

\begin{abstract}
SUMMARY
Background and Aim: Nutrition is an important social determinant of health that influences the ageing process. The aim of this study was to evaluate the nutritional condition of a group of seniors and identify the bio-psycho-social factors that increase the risk of malnutrition.

Methods: The research was conducted using a quantitative method. The standardised scales Mini Nutritional Assessment - Short Form (MNA -SF) and the Geriatric depression scale (GDS-5) were used to evaluate the nutritional condition and tendency towards depression of the tested group. This group consisted of seniors aged 75 and above living in home environment in the České Budějovice region. The group was comprised of 320 seniors, 115 men (35.9\%) and 205 women (64.1\%), which corresponds to the composition of the population in the chosen region of the Czech Republic. Statistical data analysis was conducted using SASD 1.4.10 and SPSS 15.0 programs. Pearson's chi-squared test $\left(X^{2}\right)$ and Cramér's V were chosen for statistical testing. The significance level was set at $5 \%$.

Results: The average BMI value of the seniors was $26.2 \mathrm{~kg} / \mathrm{m}^{2}$ (overweight). This value decreased with age. More than one third of the respondents were evaluated as being at risk of malnutrition (36.3\%). Unintended weight loss was determined as the strongest risk factor of malnutrition. Seniors who had lowered their food intake stated unintended weight loss 10 times more often than respondents with no noticeable reduction in food intake. Seniors who showed signs of depression indicated weight loss three and a half times more often than respondents without depression. Meanwhile acute illness increased the risk by three times. Depression was found to be the cause and also the consequence of malnutrition.

Conclusion: Despite the high prevalence of overweight and obesity, a large proportion of the respondents were running the risk of malnutrition. It was concluded that the strongest risk factors for malnutrition in the respondents were unintended weight loss, depression and lowered food intake. Compared to biological factors, social and economic factors were less significant in causing malnutrition in seniors.
\end{abstract}

Key words: malnutrition, seniors, nutritional assessment, nourishment, risk factors

Address for correspondence: I. Brabcová, Faculty of Health and Social Studies of the University of South Bohemia, U Výstaviště 26, 37005 České Budějovice, Czech Republic. E-mail: brabcova@zsf.jcu.cz

http://dx.doi.org/10.21101/cejph.a4283

\section{INTRODUCTION}

Malnutrition can be defined as an insufficient, excessive or unbalanced intake of energy (1-4). Although the ratio of excessive weight and obesity in the world population is increasing due to ongoing economic development, malnutrition is still mostly understood in the sense of undernourishment.

The quality, amount and caloric value of food, as well as eating habits are all important factors influencing the overall health status (5). In society, different social and economic conditions result in social inequalities in the area of nutrition, which in turn lead to inequalities in health (6). Insufficient food or lack of its variety lead to malnutrition and consequently to illnesses caused by nutritional deficiency. On the other hand, an excessive intake of high energy foods and the substitution of fresh products for industrially processed foods increase the risk of "diseases of civilization" such as metabolic syndrome, hypertension and myocardial infarction (7). One of the strategic aims of WHO program Health 2020 (8) is to improve the health of the world population and decrease the inequalities in health status. The goal for both public and state sectors is to ensure affordable, nutrition-rich, quality food for everyone. With an increase in life expectancy, demographic change calls for a major effort to ensure quality of life in our older population. A thorough understanding of the elderly as food consumers, their nutritional needs, their food perception and preferences is increasingly needed (9).

Seniors are particularly vulnerable to the excessive inequalities in nutritional status. According to the Czech Statistical Bureau (10), currently there are almost 1.7 million inhabitants aged 65 and above living in the Czech Republic, which represents 15.7\% of the total population.

Malnutrition is defined as a state characterised by an insufficient or unbalanced intake of foods $(2,11)$. Insufficient calorie 
intake, insufficient proteins and insufficient vitamins in food lead to protein-energy malnutrition, which exhibits itself in a negative nitrogen balance and loss of muscle mass (12). The prevalence of malnutrition in old age increases for those seniors living in healthcare facilities or care homes for seniors. According to Topinková (13), 20\% of seniors suffer from an insufficient intake of nutrition, with malnutrition occurring in 5-8\% of seniors aged 65 and above, and in $20-40 \%$ of those in healthcare facilities. According to Ahmed and Haboubi (2), malnutrition exists in $15 \%$ of seniors aged 65 and above who live in a home environment, for hospitalised seniors it is $23 \%$ to $60 \%$, and up to $85 \%$ for clients in senior homes. These results are further emphasized by Kalvach et al. (14), who state that all individuals who reach the age of 80 suffer at least mild symptoms of malnutrition regardless of their socioeconomic status.

Biological, physiological, mental, social, and economic risk factors are all responsible for the emergence of nutritional disorders $(2,9,15)$. Due to the loss of teeth, and a decrease in digestive and physical functions, there is often a decrease in appetite, and the inability to obtain enough nutrition for physical homeostasis is related to such conditions as frailty and the partial loss of physical functions, as well as a decrease in the quality of life (16). Malnutrition is connected to the lowered functioning of an organism, loss of bone mass, immunity dysfunction, anaemia, dysfunction of cognitive processes, prolonged wound healing, slower recovery after surgery, repeated hospitalisation, or increased mortality.

Social isolation is one of the social factors that include grief, eating habits, good availability of quality foods, poverty, and the possibility to use personal assistance, and it influence the incidence and progression of malnutrition. According to the Czech Ministry of Health, there is still insufficient public pressure with regards to the quality of food. Cheap, energy rich, yet nutritionally poor foods are still being preferred (17). This study clearly showed that the risk of malnutrition decreased by double when respondents started shopping for quality groceries instead of cheap ones (6). These results, as well as the research conducted by Hickson (15), indicate that social and economic factors are indeed important, but not the strongest risk factors for malnutrition in seniors. It is also important to state that a large number of seniors (as well as young families with children) living in the Czech Republic have insufficient financial reserves, and only one unexpected event may separate them from poverty.

The aim of this research was to evaluate the nutritional status and to identify bio-psycho-social factors (especially depression) that increase malnutrition risk in a targeted group of seniors.

\section{MATERIALS AND METHODS}

The research was carried out as a social study based on a project task using quantitative research tools. A field investigation was conducted using a controlled interview technique between an investigator and a respondent in the České Budějovice region in February 2014. The level of depression was tested using the Geriatric Depression Scale (GDS-5) (18). The Mini Nutritional Assessment - Short Form (MNA-SF) (19), which is a scale for orientation levels of nutrition, was chosen for evaluating the nutritional state, while the respondents' bodyweight according to Body Mass Index (BMI) was calculated and then divided into four categories (underweight $<18.5 \mathrm{~kg} / \mathrm{m}^{2}$, normal weight $18.5-24.9$ $\mathrm{kg} / \mathrm{m}^{2}$, overweight $25.0-29.9 \mathrm{~kg} / \mathrm{m}^{2}$, and obesity $>30.0 \mathrm{~kg} / \mathrm{m}^{2}$ ) by interviewers of the private agency. During the interview at the respondent's home the interviewers measured weight and height with portable digital scale and folding ruler. Other questions of the questionnaire proceeded from the theoretical findings about the bio-psycho-social changes in old age.

In the questionnaire, risk of depression was represented by five questions from the Geriatrics Depression Scale, which is the shortest possible screening questionnaire (18) that verifies suspected states of depression. This shortened version of GDS, which includes just five questions is according to Topinková (13) sufficiently sensitive and can accurately diagnose a depressive state. If there are two or more "depressed" answers in this screening then it is categorized as positive result.

\section{Research Group}

The targeted group chosen for this research were senior citizens of the České Budějovice region who were aged 75 and above and lived in a home environment. The group was set up by quota selection in order to be representative of citizens of České Budějovice in terms of gender and age (aged 75 and above).

The composition of the sample group, considering basic demographic characteristics was as follows. From a total of 320 respondents 115 were males (35.9\%) and 205 women (64.1\%), which corresponds to an analogous composition of the population aged 75 years or more in the district of České Budějovice.

With regards to relative frequencies, a deviation of $0.3 \%$ from the basic set was calculated which means that the research is indeed representative for the population of the České Budějovice region aged 75 and more in terms of gender. Table 1 shows different age groups in combination with groups based on gender.

In comparison to the age division of the basic group, the deviation lies below $0.5 \%$ (Table 1). It can therefore be concluded that the results are representative of the individual age groups of České Budějovice citizens aged 75 and more.

\section{Statistical Data Analysis}

The obtained data set was analysed using the statistical applications SPSS 15.0 and SASD 1.4.10. The first degree selection and contingent tables for chosen parameters of the second degree selection were analysed. If the following values were presented in the scale of answers: 'I don't know' and 'no answer', they were coded as missing values and excluded from further analysis.

Table 1. Composition of test group according to gender and age

\begin{tabular}{|l|c|c|c|c|c|c|}
\hline \multirow{2}{*}{ Age category } & \multicolumn{3}{|c|}{ Men } & \multicolumn{3}{c|}{ Women } \\
\cline { 2 - 7 } & $\mathrm{n}$ & $\%$ & $\begin{array}{c}\text { Deviation } \\
(\%)\end{array}$ & $\mathrm{n}$ & $\%$ & $\begin{array}{c}\text { Deviation } \\
(\%)\end{array}$ \\
\hline $75-79$ & 56 & 17.5 & 0.0 & 85 & 26.6 & 0.0 \\
\hline $80-84$ & 39 & 12.2 & 0.0 & 68 & 21.2 & 0.0 \\
\hline $85-89$ & 16 & 5.0 & -0.1 & 37 & 11.5 & -0.1 \\
\hline Above 89 & 4 & 1.3 & 0.0 & 15 & 4.7 & 0.5 \\
\hline Total & 115 & 36.0 & & 205 & 64.0 & \\
\hline
\end{tabular}


Pearson's chi-squared test $\left(\chi^{2}\right)$ was selected for testing the dependency of category variables. For the nominal, and also sometimes in combination with ordinal variables, Cramér's V test was used instead. The significance level of $5 \%(\alpha=0.05)$ was chosen for both tests as the level for refusal of zero hypothesis.

\section{RESULTS}

The average BMI value of the respondents was determined as $26.2 \mathrm{~kg} / \mathrm{m}^{2}$, which corresponds to the category of "overweight". The youngest age group of seniors (aged 75-79) had an average BMI value of $26.7 \mathrm{~kg} / \mathrm{m}^{2}$, and the eldest (aged 90 and above) had a value of $22.9 \mathrm{~kg} / \mathrm{m}^{2}$. Normal BMI values $(18.5-24.9 \mathrm{~kg} /$ $\mathrm{m}^{2}$ ) were found in $37.1 \%$ of respondents, while half of the respondents $(50.2 \%)$ were in the overweight category (25.0-29.9 $\left.\mathrm{kg} / \mathrm{m}^{2}\right) .10 .5 \%$ were found to be obese $\left(>30.0 \mathrm{~kg} / \mathrm{m}^{2}\right)$, and $2.2 \%$ underweight $\left(<18.5 \mathrm{~kg} / \mathrm{m}^{2}\right)$.

\section{Evaluation of Nutrition}

Based on the evaluation of the screening we can determine whether the person in question runs the risk of malnutrition or not. The results obtained show that more than one third (36.3\%) of the seniors in the target group were at risk of malnutrition and $63.7 \%$ were in good nutrition status (Table 2).

The age of a senior significantly increases the probability of malnutrition. In the youngest senior category ( $75-79$ years of age) $23.5 \%$ of respondents were found to be at risk of malnutrition. In the $80-84$ age group it was $42.7 \%$, and in the $85-89$ age group the risk was even higher (58.3\%). However, this rising trend was not found in the eldest age category ( 90 years and above) which were $54.5 \%$ of respondents. This result is interesting also because this category had eating disorder experiences. The correlation between age and risk of malnutrition was found to be statistically significant (Pearson Chi-Square - 18.636, df =3, p <0.001) (Table 2).

During the correlation analysis between the risk of malnutrition and the chosen variables, it was evaluated whether the given risk factor statistically increases the probability of a nutritional disorder. An effort was also made to evaluate the strength of the risk factor (RF) in question. The degree of RF is presented by Cramér's V number, where higher numbers indicate a higher risk. Among the strongest RF of malnutrition (of psychosomatic nature) were unintended weight loss (0.660), depression (0.618), decrease in food intake due to loss of appetite, and digestion problems or problems with chewing or swallowing (0.566). Immobility (0.492), acute illness (0.483), higher use of medication (0.247), and psycho-social isolation (0.364), all represent additional adverse circumstances that increase the probability of malnutrition. Economic reasons that were responsible for the occurrence of malnutrition in seniors were found to be less significant than other factors (0.211) (Table 3).

\section{Division of Respondents According to Screening Test GDS-5}

Results showed that suspected depression was prevalent in more than one third of the respondents $(34.7 \%)$.

Interestingly, when the correlations based on the dependence or independence of the variable "risk of depression in GDS-5" are

Table 2. Risk of malnutrition based on senior age

\begin{tabular}{|l|c|c|c|c|c|c|}
\hline \multirow{2}{*}{ Age category } & \multicolumn{2}{|c|}{ Good state of nourishment } & \multicolumn{2}{|c|}{ Possible malnutrition } & \multicolumn{2}{c|}{ Total } \\
\cline { 2 - 7 } & $\mathbf{n}$ & $\%$ & $\mathbf{n}$ & $\%$ & $\mathbf{n}$ & 141 \\
\hline $75-79$ & 108 & 76.5 & 33 & 23.5 & 107 & 100.0 \\
\hline $80-84$ & 61 & 57.3 & 46 & 42.7 & 53 & 100.0 \\
\hline $85-89$ & 22 & 41.7 & 31 & 58.3 & 19 & 100.0 \\
\hline $90+$ & 9 & 45.5 & 10 & 54.5 & 320 & 100.0 \\
\hline Total & 200 & 63.7 & 120 & 36.3 & 3 & \\
\hline
\end{tabular}

Table 3. Degree of association between the risk of malnutrition and chosen risk factors

\begin{tabular}{|l|c|c|}
\hline Risk factors of malnutrition & Cramér V & p value \\
\hline Unintended weight loss in the last 3 months & 0.660 & $<0.001$ \\
\hline Depression & 0.618 & $<0.001$ \\
\hline Lowered food intake in the last 3 months & 0.566 & $<0.001$ \\
\hline Immobility & 0.492 & $<0.001$ \\
\hline Acute illness & 0.483 & $<0.001$ \\
\hline Social isolation (feeling of loneliness) & 0.364 & 0.001 \\
\hline Use of more than three types of medication & 0.247 & $<0.001$ \\
\hline Consumption of less than three meals a day & 0.225 & 0.003 \\
\hline Preference of low price of food to its quality & 0.211 & 0.005 \\
\hline Insufficient daily intake of fruit & 0.192 & 0.044 \\
\hline Insufficient daily intake of vegetables & 0.185 & 0.034 \\
\hline
\end{tabular}


compared, it is not always possible to decide whether depression is the cause or the result of malnutrition. If the cause of a possible depression is the malnutrition, the situation of about $20 \%$ of the seniors can be explained by the fact. However, this variable can also be applied in reverse - when the assessment of a depressive state is presumed to be caused by the risk of malnutrition. This explains almost $30 \%$ of the senior condition cases.

\section{DISCUSSION}

This research was aimed at identifying the risk factors of malnutrition in a group of seniors aged 75 and above who live in a home environment. The cause of malnutrition is multifactorial, dependent on several biological and physiological factors as well as on the social and economic conditions in which the given person lives and is influenced by. The results show that more than one third of the seniors addressed are at risk of malnutrition (36.3\%). These values correspond to the conclusions reached by Topinková (13) and Kalvach et al. (14), who point out the gravity of malnutrition occurring amongst the senior population. The study also confirmed a positive correlation between the risk of malnutrition and the age of the respondent.

Malnutrition is not necessarily a consequence of the biological and physiological changes of an organism that are related to aging. However, according to Hickson (15) these changes can significantly increase the risk of nutritional disorders occurring at an older age. According to Wurtman et al. (20) the average daily food intake decreases by up to one third between the ages of 20 and 85. A combination of loss of appetite and lowered energy intake often leads to old age anorexia. In this study, a quarter of respondents reported to be eating less than three meals a day. Almost half of the respondents had experienced lowered food ingestion within the three months prior to the study, due to loss of appetite, digestive problems or troubles with chewing or swallowing. By consuming less than three meals a day, or reporting a dysfunction of food ingestion, these respondents were exposing themselves to a statistically significant increase of malnutrition risk.

Lowered ingestion means an insufficient intake of calorie balanced food. It can be caused by acute or chronic illness of both somatic and psychological origin. Seniors reported an unintended weight loss ten times more often than respondents without these complications. Seniors showing signs of depression reported weight loss three and a half times more often than respondents without depression. While acute disease was shown to increase weight loss threefold. Pathological causes of unintended weight loss (and consequently malnutrition) increase with age, therefore, it is important to prevent or at least quickly and suitably treat any respiratory, cardiovascular or endocrinology complaints in elderly people. Not fitting dentures can impact both the amount of food consumed and the quality, and these complications can be easily prevented. The risk of malnutrition is also connected to social and economic factors, such as poverty, social isolation, depression and decreased autonomy which in turn are all connected to lack of appetite (21).

Depression develops in 7-15\% of elderly people aged 65 and above who are living in a community. Higher numbers are found among hospitalised seniors and those in long-term care (20-30\%) (13). Hickson (15) states that depression and grief in the elderly caused by the loss of a person who was close to them often results in a loss of appetite and weight as well as in malnutrition. Hickson's study identifies symptoms of depression as the second most influential risk factor for digestion disorder among seniors. It also shows that more than one third of the respondents most probably suffer from depression. Interestingly, it was very difficult to determine whether the risk of malnutrition is the cause or consequence of the depressive state. One fifth of the respondents suffered from depression due to malnutrition while one third were at the risk of malnutrition due to depression.

This research shows that the use of more than three types of medicine simultaneously causes a twofold increase in the risk of malnutrition.

Sufficient intake of fruit and vegetables is connected to decreased morbidity as well as mortality. On the contrary, a low intake of fruit and vegetables is connected to an increased risk of cardiovascular and cancerous disease. The recommended intake comprises five portions of fruit and vegetable daily. Although most adults consume at least one portion of fruit and vegetable daily, half of the seniors never receive the recommended five daily helpings $(22,23)$. This research indicated that daily intake of fruit and vegetable decreases the risk of malnutrition. In cases where seniors reported a daily intake of fruit and vegetables, the risk of malnutrition was half that of individuals who reported an insufficient intake of fruit and vegetables.

The trend that the BMI in the Czech population increases with age but decreases again after the age of 65 (24) was confirmed in our study. The average BMI of the respondents who were 75+ was calculated as $26.2 \mathrm{~kg} / \mathrm{m}^{2}$, which falls into the overweight category. One significant finding was that while mortality from cardiovascular diseases continuously decreases for those aged less than 65 , in the past few years it has been growing for the age group of 65 and above (24). Surprisingly, despite the high incidence of excessive weight and obesity in the respondents (60.7\%), many were still at risk of malnutrition (36.3\%). The results indicate that the targeted group is mainly at risk of malnutrition due to unwanted weight loss, the presence of mental depression and a lowered food intake.

\section{CONCLUSION}

Nutrition is an important indicator of the health and overall condition of seniors aged 75+, and it is influenced by many biopsycho-social factors. The positive outcome of this research is that social and economic factors were less significant in the causes of malnutrition. However, these factors still remain important determinants of health. Certain insufficiencies can be influenced by the seniors themselves, although assistance from care givers and state authorities is necessary regarding the concept of long-term health and social care at a community level. For those seniors living in a community who may be at risk of malnutrition, there are two possible interventions that can lead to a better nutritional condition. One includes the home delivery of hot meals at least once daily, for example delivery by home care nursing services. The other involves help from a nutritional consultant. Other non-dietary interventions for the prevention and treatment of malnutrition in seniors include treatment of depression, resolving of dentition complications, social inclusion and physical activities. 


\section{Acknowledgement}

The project "Social determinants of health in selected target groups" was conducted within the programme for the development of science and research at the Faculty of Health and Social Studies at the South Bohemian University in České Budějovice (number SDZ2012_002).

\section{Ethical Approval}

The aim of the research was agreed to by the Ethical committee of ZSF JU in České Budějovice. The respondents agreed to be part of the research.

\section{Conflict of Interests}

None declared

\section{REFERENCES}

1. Blössner M, de Onis M. Malnutrition: quantifying the health impact at national and local levels. Environmental burden of disease series, no. 12. Geneva: WHO; 2005.

2. Ahmed T, Haboubi N. Assessment and management of nutrition in older people and its importance to health. Clin Interv Aging. 2010 Aug 9;5:20716.

3. Topinková E, Neuwirth J. Gerontology for general practitioners. Prague: Grada; 1995. (In Czech.)

4. Dvořáčková D. Life quality for senior citizens in retirement homes Prague: Grada; 2012. (In Czech.)

5. Domingues-Faria C, Vasson MP, Goncalves-Mendes N, Boirie Y, Walrand $\mathrm{S}$. Skeletal muscle regeneration and impact of aging and nutrition. Ageing Res Rev. 2016 Mar;26:22-36.

6. Čevela R, Čeledová L, Kalvach Z, Holčík J, Kubů P. Social gerontology. Prague: Grada; 2014. (In Czech.)

7. Schuler M, Oster P. Gerontology from A to $Z$ for nurses. Prague: Grada; 2010. (In Czech.)

8. World Health Organization. Health 2020: a European policy framework supporting action across government and society for health and wellbeing [Internet]. Geneva: WHO; 2012 [cited 2014 Oct 18]. Available from: http:/www.euro.who.int/ data/assets/pdf file/0009/169803/ RC62wd09-Eng.pdf.

9. Giacalone D, Wendin K, Kremer S, Frøst MB, Bredie WLP, Olsson V, et al. Health and quality of life in an aging population - Food and beyond. Food Qual Prefer. 2016;(47):166-70.
10. Czech Statistical Office. Age structure of inhabitants in different regions [Internet]. Prague: Czech Statistical Office; 2013 [cited 2014 Oct 27]. Available from: http://vdb.czso.cz/vdbvo/tabparam.jsp?voa=tabulka\&c islotab=DEM0040PU_KR\&\&kapitola_id=19. (In Czech.)

11. Sampson G. Weight loss and malnutrition in the elderly - the shared role of GPs and APDs. Aust Fam Physician. 2009 Jul;38(7):507-10.

12. Hrnčiariková $D$, Jurašková $B$, Zadák Z. Sarcopenia in old age. Lékařské listy. 2008;58(19):18-21. (In Czech.)

13. Topinková E. Geriatrics in practice. Prague: Galén; 2005. (In Czech.)

14. Kalvach Z, Zadák Z, Jirák R, Zavázalová H, Sucharda P, et al. Geriatrics and gerontology. Prague: Grada; 2004. (In Czech.)

15. Hickson M. Malnutrition and ageing. Postgrad Med J. 2006 Jan;82(963):28.

16. Kido Y. The issue of nutrition in an aging society. J Nutr Sci Vitaminol (Tokyo). 2015;61 Suppl:S176-7.

17. Health 2020 - national strategy for the protection and support of health and illness prevention. Prague: Ministry of Health of the Czech Republic; 2014. (In Czech.)

18. Hoyl MT, Alessi CA, Harker JO, Josephson KR, Pietruszka FM, Koelfgen $\mathrm{M}$, et al. Development and testing of a five-item version of the Geriatric Depression Scale. J Am Geriatr Soc. 1999 Jul;47(7):873-8.

19. Rubenstein LZ, Harker JO, Salvà A, Guigoz Y, Vellas B. Screening for undernutrition in geriatric practice: developing the short-form mininutritional assessment (MNA-SF). J Gerontol A Biol Sci Med Sci. 2001 Jun;56(6):M366-72

20. Wurtman JJ, Lieberman H, Tsay R, Nader T, Chew B. Calorie and nutrient intakes of elderly and young subjects measured under identical conditions. J Gerontol. 1988 Nov;43(6):B174-80.

21. Donini LM, Savina C, Cannella C. Eating habits and appetite control in the elderly: the anorexia of aging. Int Psychogeriatr. 2003 Mar;15(1):7387.

22. Nicklett EJ, Kadell AR. Fruit and vegetable intake among older adults: a scoping review. Maturitas. 2013 Aug;75(4):305-12.

23. Drewnowski A, Shultz JM. Impact of aging on eating behaviors, food choices, nutrition, and health status. J Nutr Health Aging. 2001;5(2):75-9.

24. Institute of Health Information and Statistics of the Czech Republic. European Health Interview Survey in the Czech Republic EHIS 2008. Prague: IHIS CR; 2011. (In Czech.) 